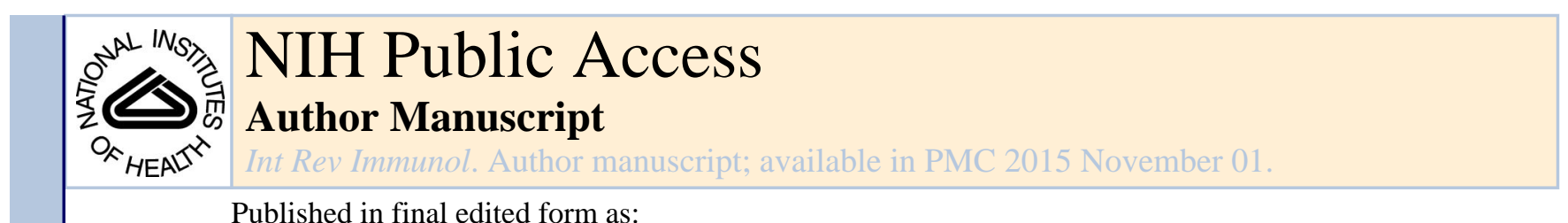

Published in final edited form as:

Int Rev Immunol. 2014 ; 33(6): 498-510. doi:10.3109/08830185.2014.889129.

\title{
The role of the liver in sepsis
}

\author{
Jun Yan, \\ Department of Paediatrics Research, The University of Texas MD Anderson Cancer Centre, \\ Houston, TX, 77030, USA \\ Song $\mathbf{L i}$, and \\ School of Pharmacy, University of Pittsburgh, Pittsburgh, PA, 15261, USA \\ Shulin Li \\ Department of Paediatrics Research, The University of Texas MD Anderson Cancer Centre, \\ Houston, TX, 77030, USA
}

\section{Abstract}

Despite the progress made in the clinical management of sepsis, sepsis morbidity and mortality rates remain high. The inflammatory pathogenesis and organ injury leading to death from sepsis are not fully understood for vital organs, especially the liver. Only recently has the role of the liver in sepsis begun to be revealed. Pre-existing liver dysfunction is a risk factor for the progression of infection to sepsis. Liver dysfunction after sepsis is an independent risk factor for multiple organ dysfunction and sepsis-induced death. The liver works as a lymphoid organ in response to sepsis. Acting as a double-edged sword in sepsis, the liver-mediated immune response is responsible for clearing bacteria and toxins but also causes inflammation, immunosuppression, and organ damage. Attenuating liver injury and restoring liver function lowers morbidity and mortality rates in patients with sepsis. This review summarizes the central role of liver in the host immune response to sepsis and in clinical outcomes.

\section{Keywords}

Sepsis; Liver injury; Inflammation; Immunosuppression; Bacterial clearance; Liver failure

\section{Introduction}

Sepsis is the most common cause of patient mortality in intensive care units, with a global incidence of approximately 18 million cases per year and a mortality rate of $28-40 \%$ [1]. The annual number of sepsis-related deaths in the United States reached 258,000 in 2009, according to Sepsis Alliance (an organization whose goal is to raise awareness of this condition to facilitate its early detection and treatment for successful outcomes). Sepsis is a dysregulated systemic inflammatory response triggered by infection, trauma, or a toxin. In patients, the response progresses from inflammation to sepsis, to severe sepsis, to septic

Address requests for reprints to: Shulin Li, Department of Paediatrics Research, Unit 0853, The University of Texas MD Anderson Cancer Centre, 1515 Holcombe Blvd., Houston, TX 77030, USA. SLi4@mdanderson.org.

Competing interests: The authors have no competing interests. 
shock, and to multiple organ dysfunction syndrome. Individuals with a weakened immune system—infants, children, and the elderly (over 65 years) — are the most susceptible to sepsis and sepsis-associated death [2]. Cancer patients are nearly 10 times more susceptible to sepsis than are patients without cancer, and sepsis-caused deaths account for $8.5 \%$ of all deaths among cancer patients [3].

A modern view of sepsis was pioneered by Semmelweis, Pasteur, and Lister in the 19th century [4]. Since then, an enormous amount of sepsis research has been conducted, including work on pathogens, coagulation cascades, immune responses, and organ damage [5-7]. The progress in these areas has improved our knowledge of the pathogenesis of sepsis. Despite this progress, sepsis mortality and morbidity rates remain high. The incidence of sepsis is expected to grow $1.5 \%$ annually because of the growing number of elderly patients, who are more susceptible to sepsis. Studies have predicted that by the year 2029, the annual number of sepsis cases may increase from the number in 2001 by as much as 50\% [8]. Progress in developing curative sepsis therapy will require an in-depth understanding of the inflammatory pathogenesis of sepsis and organ dysfunction.

The liver is the largest gland in the human body and plays a central role in metabolic and immunological homeostasis. This organ is responsible for over 200 functions, such as detoxification, storage, energy production, nutrient conversion, hormonal balance, and coagulation. These important physiological functions make the liver a critical organ for host survival following severe injury such as sepsis. Evidence has shown that liver dysfunction and failure, particularly serious complications in sepsis, directly contribute to disease progression and death [9]. This review will examine the mechanism of the liver's immune response in promoting sepsis and the effects on clinical outcomes as well as the importance of the liver's function in the diagnosis and treatment of sepsis.

\section{Types of liver injury in sepsis}

In sepsis, the liver is injured by pathogens, toxins, or inflammatory mediators. The injury progresses from active hepatocellular dysfunction to liver damage and then to liver failure. Liver dysfunction consists of subtle alterations in hepatocellular functions, such as decreased synthesis or decreased clearance function. Liver damage is defined as an irreversible injury to hepatocytes. Liver failure is defined as sustained, severe damage to the liver and loss of function in 80-90\% of liver cells [10]. Because liver damage is difficult to quantify through clinical examination and laboratory values, this review focuses mainly on liver dysfunction and liver failure.

Liver dysfunction often occurs in early sepsis; for example, liver dysfunction usually occurs 1.5 hours after cecal ligation and puncture (CLP) - a procedure of ligation below the ileocecal valve after midline laparotomy and followed by needle puncture of the cecum to induce sepsis - in animals or on the day of the sepsis diagnosis $(<24$ hours post-onset of the disease) in patients because of inflammation and hypoperfusion [11]. Ongoing inflammation and hypoperfusion can cause liver damage and failure [9]. Clinical and experimental data suggest that liver dysfunction is an early sign of sepsis, and early hepatic dysfunction in patients with sepsis is a specific and independent risk factor for poor outcome [12]. 


\section{Clinical impact of the liver in sepsis}

Because of the multiple functions of the liver in sepsis, liver injury before or after the onset of sepsis has a critical effect on the severity and outcome of sepsis in patients. The incidences of sepsis-associated liver dysfunction and liver failure range from $34 \%$ to $46 \%$ and from $1.3 \%$ to $22 \%$, respectively, in all patients with sepsis (Table 1) [13-20]. The mean incidence of liver dysfunction in patients with sepsis is $39.9 \%$, lower than the incidences of respiratory, renal, and neurological dysfunction and almost the same as the incidence of cardiovascular dysfunction. Liver failure occurs in $8.5 \%$ of patients with sepsis. The lower incidence of liver failure than the incidence of failure of other organs may be related to the liver's ability to withstand assaults and to its high regenerative capacity, which is activated in patients with sepsis but impaired in sepsis patients who also experience liver failure [21]. However, liver dysfunction and failure are associated with grave complications in sepsis. Mortality rates among sepsis patients with liver dysfunction or failure range from $54 \%$ to $68 \%$, higher than the mortality rates of sepsis patients with respiratory system dysfunction or failure (the most common organ failure in sepsis) (Table 2) [14, 15, 19]. Taken together, these data suggest that the liver plays a pivotal role in patient survival and recovery following sepsis injury.

In patients with liver failure or chronic liver conditions such as cirrhosis, trauma, and druginduced liver injury, the risks of developing sepsis, multiple organ failure (MOF), and sepsis-induced death are higher than those risks in patients without intrinsic liver diseases [22,9]. In patients with liver disease, the risk of morbidity is 30-50\%, much higher than the 5-7\% sepsis morbidity rate in the general population of hospitalized patients [23]. The inhospital mortality rate of cirrhosis patients with septic shock is as high as 70\% [24]. In patients with trauma, severe injury of the liver is associated with a higher incidence of sepsis, MOF, and mortality than the incidence in patients with severe injury of the abdomen or other organs (sepsis, $19.9 \%$ vs. $11 \%$; MOF, $32.7 \%$ vs. $16.6 \%$; mortality, $34.9 \%$ vs. $12 \%$ ) [25]. Alcohol dependence is also an independent risk factor for sepsis and associated mortality [22]. Patients with alcohol-abuse disorders often have liver dysfunction or severe comorbidities such as cirrhosis. Individuals with alcohol dependence have higher rates of sepsis ( $12.9 \%$ vs. $7.6 \%)$, organ failure $(67.3 \%$ vs. $45.8 \%)$, septic shock (3.6\% vs. $2.1 \%)$, and mortality (9.4\% vs. $7.5 \%)$ than do those without alcohol dependence [24]. Liver injury is an independent risk factor for sepsis morbidity and sepsis-associated death.

\section{Pathology of liver injury in sepsis}

Liver injury in sepsis is confirmed by histological changes in the liver. Liver dysfunction is not necessarily accompanied by significant histological changes in the liver, but liver damage and liver failure usually are. In autopsy studies, hepatitis and liver steatosis were found in the majority of patients who died of sepsis. Hepatic lesions included portal inflammation, centrilobular necrosis, lobular inflammation, hepatocellular apoptosis, cholangitis/cholangiolitis, and steatosis [26]. Some biopsy results showed mixed hepatiticcholestatic liver injuries [26]. 
The pathology of sepsis-associated liver injuries has been well studied with animal models. The early responses of the liver to CLP-induced sepsis in rats consist of suppressed liver functions such as glucose metabolism, drug detoxification, and oxidization without significant histological changes. Changes in the hepatic transcriptome, such as those in metabolic processes, occurred 6 hours after sepsis initiation in a rat sepsis model. Fifteen hours after sepsis initiation, the sepsis animals exhibited a profound conjugation defect with elevated unconjugated bile acids. Following these molecular, biochemical, and physiological changes, steatosis, cholestasis, and hepatocellular injury were observed, which is associated with hepatocyte apoptosis, necrosis, and neutrophil accumulation [27]. Hepatocyte regeneration has also been noted in moderate sepsis but not in the severe sepsis CLP model [28].

In patients, early manifestations of hepatic dysfunction include elevated serum bilirubin and alkaline phosphatase levels, and the late phase may be marked by elevation of transaminases after prolonged hypotension $[15,13]$. The rate of indocyanine green plasma disappearance and the levels of plasma bile acids (e.g. chenodeoxycholic acid and taurodeoxycholic acid) may be good markers for detecting septic liver dysfunction [29,30,11]. Many other biomarkers, such as glutathione S-transferase A1-1 [31], carbamoyl phosphate synthetase 1 [32], and glucose 6-phosphatase [33], can also indicate liver dysfunction in early sepsis. The main histological changes are spotty necrosis, capsular inflammation, portal inflammation, ballooning degeneration, and steatosis (Figure 1) [27]. Hepatic fibrosis has also occurred in experimentally induced, long-term sepsis in mice [34].

\section{Liver immune response in sepsis}

As the largest solid organ in the body, the liver has multiple major tasks, such as digastric, metabolic, hormonal, and host-defence activities, and plays a pivotal role in maintaining normal systemic homeostasis. In sepsis, the liver plays critical roles in clearing bacteria, in mediating inflammatory responses, and in coagulating, which may regulate renal failure, acute lung injury, acute respiratory distress syndrome, coagulopathy, and hepatic encephalopathy. The liver-mediated immune response to sepsis acts as a double-edged sword: it clears bacteria and toxins but causes inflammation, immunosuppression, and organ damage. We will focus on the role of the immune response mediated by the liver in the pathogenesis of sepsis.

\section{Bacterial clearance}

In patients with sepsis, mortality, immune response severity, and liver injury are correlated with bacterial and/or toxin levels. Bacterial clearance is the most important process for the survival of patients with sepsis. As the organ responsible for sterilizing and detoxifying the bloodstream, the liver plays a critical role in bacterial and toxin clearance in sepsis [35]. Over $60 \%$ of total bacteria administered in an animal model via intravenous injection can be cleared from the bloodstream and trapped in the liver 10 minutes post-injection; over $80 \%$ of the bacteria can be trapped in the liver 6 hours later. ${ }^{34}$ Lipopolysaccharide (LPS), the key inducer of inflammation in bacterial infection, is also cleared mainly by the liver [36]. 
Liver injury is associated with an increased risk of bacteremia owing to the failure to clear the bacteria. Cirrhosis is an independent risk factor for developing bacterial infection [23]. Ashare et al. [37] found that cirrhosis impaired bacterial clearance from the bloodstream, as evidenced by bacteremia following tooth brushing [37]. However, patients with chronic obstructive pulmonary disease were able to clear the bacteria as rapidly as did healthy control subjects. This observation suggests that liver function, not lung function, is critical for bacterial clearance. Liver dysfunction is accompanied by impairment to the reticuloendothelial system, to neutrophil phagocytic and intracellular killing abilities, to complement production, and to antigen presentation ability (downregulation of monocyte human leukocyte antigen DR expression), which results in impaired bacterial clearance [38]. Reduced bacterial clearance from the bloodstream is associated with more severe liver injury.

Multiple types of cells in the liver play a role in bacterial phagocytosis and clearance [35]. Liver cells, including Kupffer cells, liver sinusoidal endothelial cells (LSECs), and stellate cells, are the first line of defence against blood-borne bacteria, protecting the whole body and the liver itself. The hepatic reticuloendothelial system traps and eliminates bacteria quickly and efficiently. Kupffer cells exhibit a pronounced endocytic and phagocytic capacity for clearing bacteria and soluble bacterial products [7]. This effect requires the detection of pathogens by pattern-recognition receptors. When the expression of Toll-like receptor 4 (TLR4) was specifically eliminated from myeloid cells (macrophages and neutrophils), phagocytosis and bacterial clearance of Kupffer cells were impaired post-CLP [36].

Kupffer cells also cooperate with platelets and neutrophils in clearing bacteria from the bloodstream [39]. When bacteria are captured on the Kupffer cells, the patrolling platelets firmly adhere to the cells, as glycoprotein Ib on the platelets interacts with the von Willebrand factor on the cells. The aggregation of platelets increases the likelihood of detecting bacteria and limiting their escape from Kupffer cells [39]. Neutrophils migrate to and accumulate in liver sinusoids via chemokines secreted by Kupffer cells during endotoxemia and sepsis. Then neutrophils and platelets interact with each other, promoting the release of neutrophil extracellular traps to capture and eliminate the microbes [39].

B cells in the liver also participate in phagocytosis and bacterial clearance [40]. Nakashima et al. [40] found that mouse liver B cells positive for immunoglobulin M can behave like Kupffer cells to phagocytose bacteria. B cells in other organs, such as those in the spleen, do not show this function. Hepatocytes also have phagocytic action when pathogens break up the barrier of LSECs [41,42]. Thus, many cells in the liver have the ability to phagocytose and clear bacteria, thereby preventing sepsis-related systemic organ damage.

Most free or lipoprotein-bound LPS is taken up by Kupffer cells through scavenger receptors (for example, SR-A) and inactivated by acyloxyacyl hydrolase, which is produced within the liver by Kupffer cells [43]. Hepatocytes also contribute to LPS clearance by primarily using lipoprotein. LPS-binding protein transfers LPS to CD14, thus facilitating the interaction between LPS and TLR4 on the surface of phagocytes to remove LPS and initiate the pro-inflammatory cascade [44]. In one study, TLR4 knockout murine hepatocytes failed 
to clear LPS, resulting in augmented inflammation and organ injury in both polymicrobial sepsis and endotoxemia [36].

\section{Liver-mediated pro-inflammatory response}

Bacterial and toxin clearance is associated with an inflammatory response in sepsis. In patients with sepsis, the liver can act as a source of inflammatory mediators. The liver is the major site of inflammatory responses to bacterial endotoxins during sepsis. Siore et al. [45] used an in situ circuit in piglets to perfuse the ventilated lung or both the lung and the liver with LPS to determine the role of the liver in endotoxin-induced lung injury. The researchers found that the endotoxin only induced pulmonary hypertension and neutropenia and minimally elevated tumour necrosis factor alpha (TNF-a), interleukin (IL)-6, and nitric oxide (NO) without lung oedema when only the lung was perfused. However, when the liver was included in the perfusion, the endotoxin caused marked hypoxemia and lung oedema with dramatically increased TNF-a, IL-6, and NO levels [45]. These findings show that when the host is exposed to endotoxins, the liver, not the lung, is the main source of production of cytokines and NO.

The injured liver can induce severe and systemic detrimental inflammatory responses in other organs during sepsis [46]. With ischemia/reperfusion hepatic injury after bacterial infection in rats, both systemic and local lung inflammation levels were higher than those in infected rats without such injury [47]. These findings indicate that liver dysfunction induced by occult changes in hepatic perfusion may amplify systemic inflammatory and lung inflammatory responses to bacterial infection in sepsis. Excess production of cytokines and NO induced other organ injuries such as acute lung injury and acute respiratory distress syndrome, which cause respiratory failure in patients with severe sepsis [46]. These findings are consistent with the excess production of cytokines in cirrhosis patients with sepsis. The high levels of pro-inflammatory cytokines are related to liver function impairment and multiple organ dysfunction syndrome [46]. Thus, the liver plays a central role in inflammation and organ injury in sepsis.

Kupffer cells are responsible for producing inflammatory cytokines in early sepsis and for mediating sepsis-induced liver injury. Following an attack by harmful bacteria and/or endotoxins, Kupffer cells increase the rate of release of several early pro-inflammatory mediators, such as TNF-a, IL-1, IL-6, interferon gamma (IFN- $\gamma$ ), IL-8, and monocyte chemoattractant protein 1 as well as secondary mediators of tissue injury, e.g. NO and reactive oxygen species [48]. Kupffer cell depletion, induced by administering gadolinium chloride before CLP, reduces the secretion rate of pro-inflammatory cytokines such as IL-1 $\beta$ and IL-6, ameliorates microcirculatory failure in the liver, decreases hepatic apoptosis, and prevents the occurrence of hepatic injury and dysfunction in rats during early sepsis (5 hours post-CLP) [48]. Thus, depleting Kupffer cells reduces the systemic inflammatory response in sepsis and helps protect the liver and distant organs from inflammation-induced injury. However, because of impaired bacterial clearance in the liver owing to the loss of Kupffer cells, the survival rate of septic animals is significantly reduced [48]. Modulating Kupffer cell hyperactivity during sepsis could be a novel approach for suppressing inflammation and protecting organs from injury. 
Hepatic natural killer T (NKT) cells play a critical stimulatory role in the development of a local and/or systemic pro-inflammatory response to sepsis. NKT cells comprise 10-20\% of the total $\mathrm{T}$ cell population in the liver, which is a much higher percentage than in other organs. NKT cells are activated in septic mice with increased expression of surface molecules (CD69 and CD25), and the frequency of NKT cells that are positive for intracellular cytokines (TNF- $\alpha$, IFN- $\gamma$, MCP-1, IL-6, IL-4, IL-10, etc.) also increases. In the early stages of sepsis, the major effect of NKT cells is pro-inflammatory, and NKT cells induce the Th1-dominant response. During chronic sepsis, the cytokine profiles of NKT cells shift to Th2-type responses upon repeated exposure to Ag. Lack of NKT cells (CD1D-/- or Jalpha 18-/- mice) or the functional blockade of NKT cell signalling with anti$\mathrm{CD} 1 \mathrm{~d}$-blocking $\mathrm{Ab}$ both lead to an obliteration of the systemic inflammatory response (with little effect on splenic/peritoneal immune responsiveness), protecting mice from septic death (the survival rate increased 35\%) [49]. Therefore, hepatic NKT cells play a critical role in regulating the systemic inflammatory response and promote survival in sepsis.

NK cells are major players in the inflammatory response during sepsis [50]. Twenty to thirty per cent of lymphocytes in the liver are NK cells. In sepsis, lethally infected mice have more NK cells in the liver, but not in the spleen, than do non-lethally infected mice (Ehrlichiainduced toxic shock model) [Stevenson, \#62]. NK cells produce high serum level of IFN- $\gamma$, TNF- $\mathrm{a}$, and IL-10, and induce severe apoptosis in liver. Also the liver injury is more severe in lethally infected mice than in non-lethally infected mice. LPS directly acts on NK cells to induce cytokine expression through TLR4-mediated signalling. Depleting NK cells with anti-NK1.1 antibody protects mice against LPS-induced sepsis death by decreasing IFN- $\gamma$ and granulocyte-macrophage colony-stimulating factor production in the liver and serum, thus minimizing tissue injury. Therefore, NK cells mediate fatal sepsis by enhancing local and systemic inflammation and by directly injuring host cells.

$\mathrm{CD} 8^{+} \mathrm{T}$ cells also play a role in inflammation and liver injury in sepsis. $\mathrm{CD} 8^{+} \mathrm{T}$ cells double in the liver after CLP in mice [51]. $\mathrm{CD} 8^{+} \mathrm{T}$ cells induce inflammation through secretion of cytokines or attack infective cells [52]. The IL-6 levels were significantly lower in septic CD8 knockout mice than in septic wild-type mice. Adoptive transfer $\mathrm{CD} 8^{+} \mathrm{T}$ cells from wild-type mice that had undergone CLP induced high levels of IL-6 secretion and liver injury in the $\mathrm{CD} 8+\mathrm{T}$ cell-deficient recipient mouse strains (severe combined immunodeficient mice or RAG1-/- mice). $\mathrm{CD} 8^{+} \mathrm{T}$ cells from septic mice also expressed Fas ligand and led to the activation of nuclear factor kappa-light-chain enhancer of activated $\mathrm{B}$ cells (NF- $\mathrm{KB}$ ) and to the transcription of pro-inflammatory cytokines [53]. In response to increased CD4+, CD8+ T cells, and other immune cells infiltration in liver, Fas and FasL is up-regulated, and apoptosis is increasing in the liver of mice underwent CLP surgery. Increased CD8+ T cells are correlated with inflammation and liver injury in sepsis.

LSECs, hepatic stellate cells, and hepatocytes also participate in the production of inflammatory and chemotactic factors. LSECs and hepatic stellate cells recognize proteins from pathogens via pattern recognition receptors, such as TLR, and act as liver antigenpresenting cells (APCs). These cells cooperate with Kupffer cells to activate NKT cells and classic $\mathrm{T}$ cells in the liver and recruit neutrophils to the liver, thereby inducing local and systemic inflammatory responses in sepsis [7]. 
Therefore, there is an increase in the cell number of CD4, CD8, NK, and NKT cells infiltrated in liver which associated with severe inflammatory response in septic mice. And excessive inflammatory responses cause hepatic cells necrosis and apoptosis which resulted in liver injury.

\section{Liver-mediated immunosuppression}

In addition to the production of pro-inflammatory cytokines, the response of the liver to sepsis involves the concomitant induction of anti-inflammatory mediators such as IL-10, transforming growth factor $\beta$, and glucocorticoids, which play a critical role in avoiding immune reactions against antigens from dietary and gut pathogens [46]. Many types of liverresident cells can exhibit immune regulatory functions and work cooperatively with circulating cells to induce liver tolerance of toxins, suppress systemic inflammatory responses, and protect organs from injury.

Induction of LPS/endotoxin tolerance/desensitization in the liver is a major mechanism of immunosuppression in sepsis. Although this effect prevents the development of sepsis or systemic inflammation, this effect also is the main contributor to immunosuppression and mortality [54]. Endotoxin tolerance has been observed in patients with sepsis, acute liver failure, and cirrhosis [55]. Monocytes down-regulate surface expression of TLR4 after LPS treatment, which reduces the inflammatory effect of LPS. When stimulated with LPS, monocytes from these patients produce less TNF- $\alpha$ and much more IL-10 than do the monocytes from healthy controls. Antigen-presenting capacity is also impaired in these tolerant cells for decreased expression of human leukocyte antigen DR and some costimulatory molecules. These cells produce anti-inflammatory cytokines instead of inflammatory cytokines to induce immunosuppression when they are exposed to further endotoxin challenge [56]. Furthermore, hepatocytes can be desensitized to LPS via inducing the expression of suppressor of cytokine signalling 1, which is a negative regulator of TLR4myeloid differentiation primary response 88 (MYD88) signalling and LPS uptake in hepatocytes. LPS tolerance can also be induced in LSECs by reducing nuclear localization of NF- $\kappa B$ upon LPS challenge [57]. LPS-tolerant LSECs also downregulate the expression levels of adhesion molecules, resulting in reduced leukocyte adhesion to the sinusoidal endothelium. When LSECs undergo tolerogenic maturation, they induce CD8 ${ }^{+} \mathrm{T}$ cell tolerance through expressing high levels of B7 homolog 1 and low levels of CD80/86 [58]. Therefore, endotoxin/LPS tolerance plays an important part in the patient's susceptibility to reinfection, which may induce death in patients with sepsis.

Myeloid-derived suppressor cells (MDSCs) recruit to the liver site in sepsis to induce immunosuppression. In normal conditions, MDSCs are prevalent in the liver (approximately $5 \%$ of all hepatic cells). In sepsis, MDSCs also accumulate in the liver site of mice after CLP or after LPS injection. CLP- or LPS- treated mice have double to triple the percentage of MDSCs in the liver than do control mice. Sander et al. [59] found that hepatocyte-specific

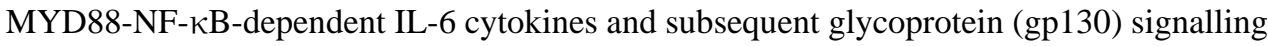
in hepatocytes are crucial for the mobilization and accumulation of MDSCs. Hepaticspecific gp130-deficient animals did not accumulate MDSCs and had increased inflammatory cytokine levels and increased mortality from sepsis. 
The MDSCs of septic mice have a great potential to control inflammatory response and to protect the liver from injury induced by inflammation [60]. Liver MDSCs have a strong suppressive effect on $\mathrm{CD}^{+}$and $\mathrm{CD} 8^{+} \mathrm{T}$ cell proliferation via secreting arginase 1 and $\mathrm{NO}$ synthase 2 . MDSCs produce anti-inflammatory IL-10 and transforming growth factor- $\beta$ and inhibit pro-inflammatory cytokine release. MDSCs also can impair dendritic cell development, block NK cell cytotoxicity, and induce the generation of T regulatory cells. Adoptive transfer of MDSCs into hepatic-specific gp130-depletion mice protected septic mice. Therefore, the MDSCs that accumulated in the livers of septic mice mediated immunosuppression and controlled inflammatory responses, thus reducing mortality rates in murine models of sepsis.

APCs in the liver are also important for inducing immune tolerance in sepsis. It has been reported that liver APCs, such as Kupffer cells, LSECs, and hepatic stellate cells, all contribute to the state of tolerance through their expression of programmed cell death 1 ligand 1 (PD-L1) and IL-10 in response to LPS and bacteria. Hepatocytes can also act like APCs with major histocompatibility complex and CD1 expression on the surface. However, hepatocytes present antigens to induce tolerance rather than to activate $\mathrm{T}$ and NKT cells because of the lack of co-stimulatory molecules and CD40 expression. T cells are exposed to an immunosuppressive microenvironment in the liver, which includes suppressive cytokines such as IL-10, transforming growth factor- $\beta$, and inhibitory molecules such as PD-L1 produced by APCs, and T cells are undergoing inhibited TCR-mediated activation, proliferation, and cytokine secretion, inducing $\mathrm{T}$ regulatory cell development and recruiting circulating $\mathrm{T}$ regulatory cells [61]. Some $\mathrm{T}$ cells are clonally eliminated by apoptosis after encountering these tolerance-inducing APCs. Therefore, the liver induces systemic tolerance by liver APCs in infection and sepsis.

It is vital to achieve a balance between pro-inflammatory and anti-inflammatory responses in the liver during sepsis. Liver Kupffer cells, NK cells, NKT cells, CD4 ${ }^{+} \mathrm{T}$ cells, MDSCs, APCs, and other liver-resident cells interact with circulatory immune cells to regulate the balance of local and systemic pro-inflammatory and anti-inflammatory responses during sepsis. Infection that induces an excessive pro-inflammatory response can lead to a systemic inflammatory response, thus promoting organ injury and patient mortality. In contrast, infection that induces abundant anti-inflammatory mediators can lead to a lack of proinflammatory response and impair the ability to clear bacteria and LPS uptake, resulting in the loss of control of infection and causing susceptibility to reinfection. Alternatively, producing a balanced pro-inflammatory and anti-inflammatory response results in bacterial clearance and resolution of inflammation, thus promoting recovery from sepsis (Figure 2). Modulating liver function and the liver immune response during sepsis could be a novel strategy for regulating systemic immune responses and protecting organs from injury induced by sepsis.

\section{Conclusions}

Despite recent therapeutic breakthroughs, mortality rates remain high in sepsis patients, and much remains to be done to advance our understanding and treatment of sepsis. The liver plays an essential regulatory role in sepsis and homeostasis. Addressing the disturbance of 
liver functions, such as immune response, metabolism, excretion, coagulation, and detoxification, is important for the prognosis and ultimate survival of sepsis patients (Figure 3) [11]. In this review, we summarized liver injury-associated morbidity and mortality in sepsis patients, discussed how liver injury promotes the progress of sepsis and affects clinical outcomes, and delineated the central role of the liver immune response in regulating homeostasis and the progress of sepsis.

Sepsis causes liver injury, and liver injury exacerbates the severity of sepsis, with each amplifying the other's effects. Attenuating liver injury and restoring the balance of liver proinflammatory and anti-inflammatory responses will lower sepsis morbidity and mortality rates by regulating systemic immune responses and protecting organs from injury. Our understanding of the pathophysiology of sepsis-associated liver injury and of the mechanisms by which liver dysfunction promotes sepsis continues to evolve. Further investigation of the liver's role in sepsis may lead to the development of new therapeutic targets and strategies.

\section{Review Criteria}

The literature cited in this article was updated at the end of October 2013 and was found by searching MEDLINE using the following terms alone and in combination: "sepsis," "shock," "multiple organ dysfunction," "liver injury," "liver dysfunction," "liver failure," "cirrhosis," "cholestasis," "bacteria clearance," "coagulation disorders," "lipopolysaccharide," "inflammation," and "immunosuppression." Only full papers published in English language journals were considered; reviews have been cited where appropriate to limit the number of references.

\section{Acknowledgments}

This work was supported by grant CA120895 from NIH. We thank Xiaohong Wang and Arun Satelli for helpful comments. We thank Arthur Gelmis and Jill Delsigne for editing this review.

\section{References}

1. Hotchkiss RS, Nicholson DW. Apoptosis and caspases regulate death and inflammation in sepsis. Nat Rev Immunol. 2006; 6(11):813-22. [PubMed: 17039247]

2. Iwashyna TJ, Cooke CR, Wunsch H, Kahn JM. Population burden of long-term survivorship after severe sepsis in older Americans. J Am Geriatr Soc. 2012; 60(6):1070-7. [PubMed: 22642542]

3. Danai PA, Moss M, Mannino DM, Martin GS. The epidemiology of sepsis in patients with malignancy. Chest. 2006; 129(6):1432-40. [PubMed: 16778259]

4. Marshall JC. Sepsis: current status, future prospects. Curr Opin Crit Care. 2004; 10(4):250-64. [PubMed: 15258497]

5. Hotchkiss RS, Monneret G, Payen D. Immunosuppression in sepsis: a novel understanding of the disorder and a new therapeutic approach. Lancet Infect Dis. 2013; 13(3):260-8. [PubMed: 23427891]

6. Crouser E, Exline M, Knoell D, Wewers MD. Sepsis: links between pathogen sensing and organ damage. Curr Pharm Des. 2008; 14(19):1840-52. [PubMed: 18691095]

7. Dhainaut JF, Marin N, Mignon A, Vinsonneau C. Hepatic response to sepsis: interaction between coagulation and inflammatory processes. Crit Care Med. 2001; 29(7 Suppl):S42-7. [PubMed: 11445733] 
8. Gaieski DF, Edwards JM, Kallan MJ, Carr BG. Benchmarking the incidence and mortality of severe sepsis in the United States*. Crit Care Med. 2013; 41(5):1167-74. [PubMed: 23442987]

9. Canabal JM, Kramer DJ. Management of sepsis in patients with liver failure. Curr Opin Crit Care. 2008; 14(2):189-97. [PubMed: 18388682]

10. Jarrar, DWP.; Chaudry, IH. Hepatocellular dysfunction-basic considerations. In: Holzheimer, RGMJ., editor. Surgical Treatment: Evidence-Based and Problem-Oriented. Munich: Zuckschwerdt; 2001.

11. Recknagel P, Gonnert FA, Westermann M, Lambeck S, Lupp A, Rudiger A, et al. Liver dysfunction and phosphatidylinositol-3-kinase signalling in early sepsis: experimental studies in rodent models of peritonitis. PLoS Med. 2012; 9(11):e1001338. [PubMed: 23152722]

12. Kramer L, Jordan B, Druml W, Bauer P, Metnitz PG. Incidence and prognosis of early hepatic dysfunction in critically ill patients--a prospective multicenter study. Crit Care Med. 2007; 35(4): 1099-104. [PubMed: 17334250]

13. Vincent JL, Angus DC, Artigas A, Kalil A, Basson BR, Jamal HH, Johnson G 3rd, Bernard GR. Effects of drotrecogin alfa (activated) on organ dysfunction in the PROWESS trial. Crit Care Med. 2003; 31(3):834-40. [PubMed: 12626993]

14. Cheng B, Xie G, Yao S, Wu X, Guo Q, Gu M, et al. Epidemiology of severe sepsis in critically ill surgical patients in ten university hospitals in China. Crit Care Med. 2007; 35(11):2538-46. [PubMed: 17828034]

15. Brun-Buisson C, Meshaka P, Pinton P, Vallet B. EPISEPSIS: a reappraisal of the epidemiology and outcome of severe sepsis in French intensive care units. Intensive Care Med. 2004; 30(4):5808. [PubMed: 14997295]

16. Blanco J, Muriel-Bombin A, Sagredo V, Taboada F, Gandia F, Tamayo L, et al. Incidence, organ dysfunction and mortality in severe sepsis: a Spanish multicentre study. Crit Care. 2008; 12(6):R158. [PubMed: 19091069]

17. Martin GS, Mannino DM, Eaton S, Moss M. The epidemiology of sepsis in the United States from 1979 through 2000. N Engl J Med. 2003; 348(16):1546-54. [PubMed: 12700374]

18. Seymour CW, Iwashyna TJ, Cooke CR, Hough CL, Martin GS. Marital status and the epidemiology and outcomes of sepsis. Chest. 2010; 137(6):1289-96. [PubMed: 20173054]

19. Angus DC, Linde-Zwirble WT, Lidicker J, Clermont G, Carcillo J, Pinsky MR. Epidemiology of severe sepsis in the United States: analysis of incidence, outcome, and associated costs of care. Crit Care Med. 2001; 29(7):1303-10. [PubMed: 11445675]

20. Bakker J, Grover R, McLuckie A, Holzapfel L, Andersson J, Lodato R, et al. Administration of the nitric oxide synthase inhibitor NG-methyl-L-arginine hydrochloride (546C 88 ) by intravenous infusion for up to 72 hours can promote the resolution of shock in patients with severe sepsis: results of a randomized, double-blind, placebo-controlled multicenter study (study no. 144-002). Crit Care Med. 2004; 32(1):1-12. [PubMed: 14707554]

21. Weiss YG, Bellin L, Kim PK, Andrejko KM, Haaxma CA, Raj N, Furth EE, Deutschman CS. Compensatory hepatic regeneration after mild, but not fulminant, intraperitoneal sepsis in rats. Am J Physiol Gastrointest Liver Physiol. 2001; 280(5):G968-73. [PubMed: 11292606]

22. Gentilello LM. Alcohol and the intensive care unit: it's not just an antiseptic. Crit Care Med. 2007; 35(2):627-8. [PubMed: 17251701]

23. Foreman MG, Mannino DM, Moss M. Cirrhosis as a risk factor for sepsis and death: analysis of the National Hospital Discharge Survey. Chest. 2003; 124(3):1016-20. [PubMed: 12970032]

24. Wong F, Bernardi M, Balk R, Christman B, Moreau R, Garcia-Tsao G, et al. Sepsis in cirrhosis: report on the 7th meeting of the International Ascites Club. Gut. 2005; 54(5):718-25. [PubMed: 15831923]

25. Lendemans S, Heuer M, Nast-Kolb D, Kuhne CA, Dammann M, Lefering R, et al. Significance of liver trauma for the incidence of sepsis, multiple organ failure and lethality of severely injured patients. An organ-specific evaluation of 24,771 patients from the trauma register of the DGU. Unfallchirurg. 2008; 111(4):232-9. [PubMed: 18351314]

26. Koskinas J, Gomatos IP, Tiniakos DG, Memos N, Boutsikou M, Garatzioti A, et al. Liver histology in ICU patients dying from sepsis: a clinico-pathological study. World J Gastroenterol. 2008; 14(9):1389-93. [PubMed: 18322953] 
27. Muftuoglu MA, Aktekin A, Ozdemir NC, Saglam A. Liver injury in sepsis and abdominal compartment syndrome in rats. Surg Today. 2006; 36(6):519-24. [PubMed: 16715421]

28. Akcan A, Kucuk C, Ok E, Canoz O, Muhtaroglu S, Yilmaz N, Yilmaz Z. The effect of amrinone on liver regeneration in experimental hepatic resection model. J Surg Res. 2006; 130(1):66-72. [PubMed: 16154150]

29. Gonnert F, Bauer M, Kortgen A. Current aspects of diagnostics of hepatic dysfunction in critically ill. Dtsch Med Wochenschr. 2012; 137(43):2212-6. [PubMed: 23076668]

30. Memis D, Kargi M, Sut N. Effects of propofol and dexmedetomidine on indocyanine green elimination assessed with LIMON to patients with early septic shock: a pilot study. J Crit Care. 2009; 24(4):603-8. [PubMed: 19931154]

31. Koo DJ, Zhou M, Chaudry IH, Wang P. Plasma alpha-glutathione S-transferase: a sensitive indicator of hepatocellular damage during polymicrobial sepsis. Arch Surg. 2000; 135(2):198-203. [PubMed: 10668881]

32. Crouser ED, Julian MW, Huff JE, Struck J, Cook CH. Carbamoyl phosphate synthase-1: a marker of mitochondrial damage and depletion in the liver during sepsis. Crit Care Med. 2006; 34(9): 2439-46. [PubMed: 16791110]

33. Maitra SR, Wang S, Brathwaite CE, El-Maghrabi MR. Alterations in glucose-6-phosphatase gene expression in sepsis. J Trauma. 2000; 49(1):38-42. [PubMed: 10912855]

34. Gonnert FA, Kunisch E, Gajda M, Lambeck S, Weber M, Claus RA, et al. Hepatic Fibrosis in a Long-term Murine Model of Sepsis. Shock. 2012; 37(4):399-407. [PubMed: 22266973]

35. Protzer U, Maini MK, Knolle PA. Living in the liver: hepatic infections. Nat Rev Immunol. 2012; 12(3):201-13. [PubMed: 22362353]

36. Deng M, Scott MJ, Loughran P, Gibson G, Sodhi C, Watkins S, Hackam D, Billiar TR. Lipopolysaccharide clearance, bacterial clearance, and systemic inflammatory responses are regulated by cell type-specific functions of TLR4 during sepsis. J Immunol. 2013; 190(10):515260. [PubMed: 23562812]

37. Ashare A, Stanford C, Hancock P, Stark D, Lilli K, Birrer E, et al. Chronic liver disease impairs bacterial clearance in a human model of induced bacteremia. Clin Transl Sci. 2009; 2(3):199-205. [PubMed: 20443893]

38. Wasmuth HE, Kunz D, Yagmur E, Timmer-Stranghoner A, Vidacek D, Siewert E, et al. Patients with acute on chronic liver failure display "sepsis-like" immune paralysis. J Hepatol. 2005; 42(2): 195-201. [PubMed: 15664244]

39. Wong CH, Jenne CN, Petri B, Chrobok NL, Kubes P. Nucleation of platelets with blood-borne pathogens on Kupffer cells precedes other innate immunity and contributes to bacterial clearance. Nat Immunol. 2013

40. Rauch PJ, Chudnovskiy A, Robbins CS, Weber GF, Etzrodt M, Hilgendorf I, et al. Innate response activator B cells protect against microbial sepsis. Science. 2012; 335(6068):597-601. [PubMed: 22245738]

41. Soji T, Murata Y, Ohira A, Nishizono H, Tanaka M, Herbert DC. Evidence that hepatocytes can phagocytize exogenous substances. Anat Rec. 1992; 233(4):543-6. [PubMed: 1626713]

42. Kirn A, Steffan AM, Anton M, Gendrault JL, Bingen A. Phagocytic properties displayed by mouse hepatocytes after virus induced damage of the sinusoidal lining. Biomedicine. 1978; 29(1):25-8. [PubMed: 667283]

43. Seternes T, Dalmo RA, Hoffman J, Bogwald J, Zykova S, Smedsrod B. Scavenger-receptormediated endocytosis of lipopolysaccharide in Atlantic cod (Gadus morhua L.). J Exp Biol. 2001; 204(Pt 23):4055-64. [PubMed: 11809780]

44. Shao B, Munford RS, Kitchens R, Varley AW. Hepatic uptake and deacylation of the LPS in bloodborne LPS-lipoprotein complexes. Innate Immun. 2012; 18(6):825-33. [PubMed: 22441700]

45. Siore AM, Parker RE, Stecenko AA, Cuppels C, McKean M, Christman BW, et al. Endotoxininduced acute lung injury requires interaction with the liver. Am J Physiol Lung Cell Mol Physiol. 2005; 289(5):L769-76. [PubMed: 16006484]

46. Gustot T, Durand F, Lebrec D, Vincent JL, Moreau R. Severe sepsis in cirrhosis. Hepatology. 2009; 50(6):2022-33. [PubMed: 19885876] 
47. Matuschak GM, Henry KA, Johanns CA, Lechner AJ. Liver-lung interactions following Escherichia coli bacteremic sepsis and secondary hepatic ischemia/reperfusion injury. Am J Respir Crit Care Med. 2001; 163(4):1002-9. [PubMed: 11282780]

48. Koo DJ, Chaudry IH, Wang P. Kupffer cells are responsible for producing inflammatory cytokines and hepatocellular dysfunction during early sepsis. J Surg Res. 1999; 83(2):151-7. [PubMed: 10329110]

49. Hu CK, Venet F, Heffernan DS, Wang YL, Horner B, Huang X, et al. The role of hepatic invariant NKT cells in systemic/local inflammation and mortality during polymicrobial septic shock. $\mathrm{J}$ Immunol. 2009; 182(4):2467-75. [PubMed: 19201902]

50. Souza-Fonseca-Guimaraes F, Cavaillon JM, Adib-Conquy M. Bench-to-bedside review: Natural killer cells in sepsis - guilty or not guilty? Crit Care. 2013; 17(4):235. [PubMed: 23998530]

51. Wesche-Soldato DE, Chung CS, Gregory SH, Salazar-Mather TP, Ayala CA, Ayala A. CD8+ T cells promote inflammation and apoptosis in the liver after sepsis: role of Fas-FasL. Am J Pathol. 2007; 171(1):87-96. [PubMed: 17591956]

52. Bertoletti A, Maini M, Williams R. Role of hepatitis B virus specific cytotoxic T cells in liver damage and viral control. Antiviral Res. 2003; 60(2):61-6. [PubMed: 14638399]

53. Condotta SA, Rai D, James BR, Griffith TS, Badovinac VP. Sustained and incomplete recovery of naive CD8+ T cell precursors after sepsis contributes to impaired CD8+ T cell responses to infection. J Immunol. 2013; 190(5):1991-2000. [PubMed: 23355736]

54. Li F, Tian Z. The liver works as a school to educate regulatory immune cells. Cell Mol Immunol. 2013; 10(4):292-302. [PubMed: 23604044]

55. von Baehr V, Docke WD, Plauth M, Liebenthal C, Kupferling S, Lochs H, Baumgarten R, Volk HD. Mechanisms of endotoxin tolerance in patients with alcoholic liver cirrhosis: role of interleukin 10, interleukin 1 receptor antagonist, and soluble tumour necrosis factor receptors as well as effector cell desensitisation. Gut. 2000; 47(2):281-7. [PubMed: 10896923]

56. Broad A, Jones DE, Kirby JA. Toll-like receptor (TLR) response tolerance: a key physiological "damage limitation" effect and an important potential opportunity for therapy. Curr Med Chem. 2006; 13(21):2487-502. [PubMed: 17017906]

57. Uhrig A, Banafsche R, Kremer M, Hegenbarth S, Hamann A, Neurath M, et al. Development and functional consequences of LPS tolerance in sinusoidal endothelial cells of the liver. J Leukoc Biol. 2005; 77(5):626-33. [PubMed: 15860798]

58. Diehl L, Schurich A, Grochtmann R, Hegenbarth S, Chen L, Knolle PA. Tolerogenic maturation of liver sinusoidal endothelial cells promotes B7-homolog 1-dependent CD8+ T cell tolerance. Hepatology. 2008; 47(1):296-305. [PubMed: 17975811]

59. Sander LE, Sackett SD, Dierssen U, Beraza N, Linke RP, Muller M, et al. Hepatic acute-phase proteins control innate immune responses during infection by promoting myeloid-derived suppressor cell function. J Exp Med. 2013; 207(7):1453-64. [PubMed: 20530204]

60. Ren D, Bi Q, Li L, Gao Y, Liang Y, Li Y, et al. Myeloid-derived suppressor cells accumulate in the liver site after sepsis to induce immunosuppression. Cell Immunol. 2013; 279(1):12-20. [PubMed: 23026740]

61. Biswas SK, Lopez-Collazo E. Endotoxin tolerance: new mechanisms, molecules and clinical significance. Trends Immunol. 2009; 30(10):475-87. [PubMed: 19781994] 


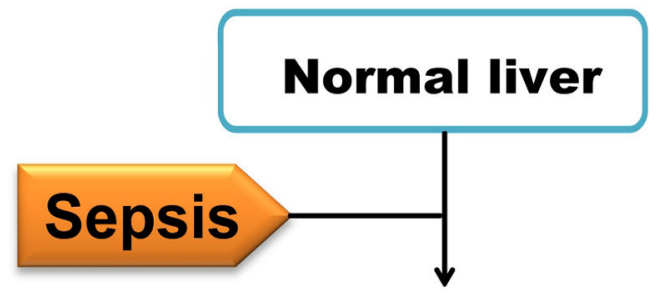

Hypoxia and inflammation

$\downarrow$\begin{tabular}{l|l|l} 
Impaired \\
function
\end{tabular}$\quad \begin{aligned} & \text { Cell death } \\
& \text { apoptosis } \\
& / \text { necrosis }\end{aligned} \quad \downarrow \begin{gathered}\text { Activation } \\
\text { of HSCs }\end{gathered}$

\section{Steatosis}

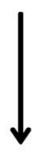

Cholestasis
Spotty necrosis, Ballooning degeneration

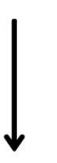

Hepatitis

\section{Fibrosis}

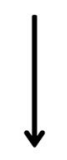

Cirrhosis

Figure 1.

Pathological changes in the liver in patients with sepsis. Abbreviations: HSCs, hepatic stellate cells. 


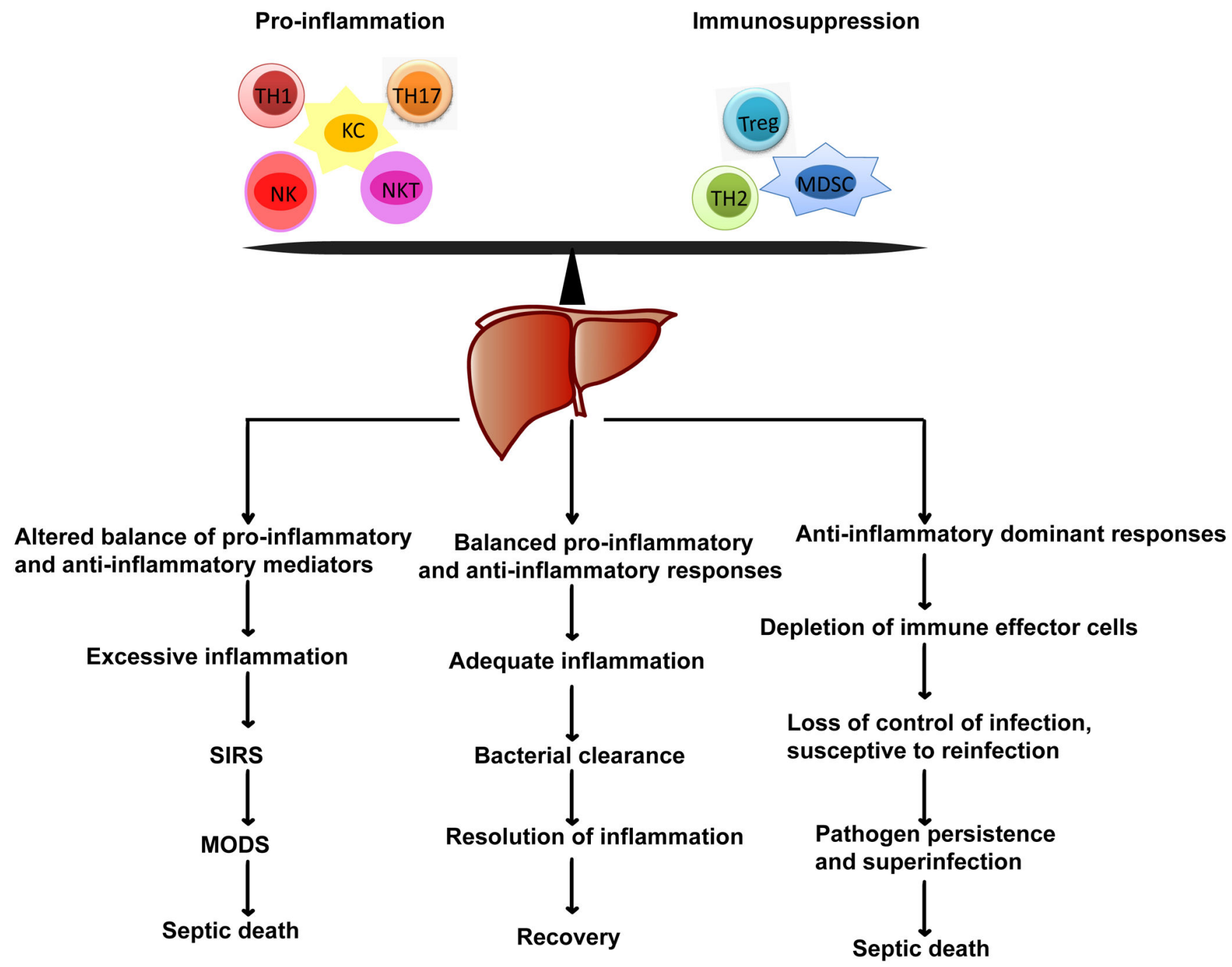

Figure 2.

The balance of pro-inflammatory and immunosuppressive response in the liver is critical for regulating the systemic immune responses and outcome of sepsis. 


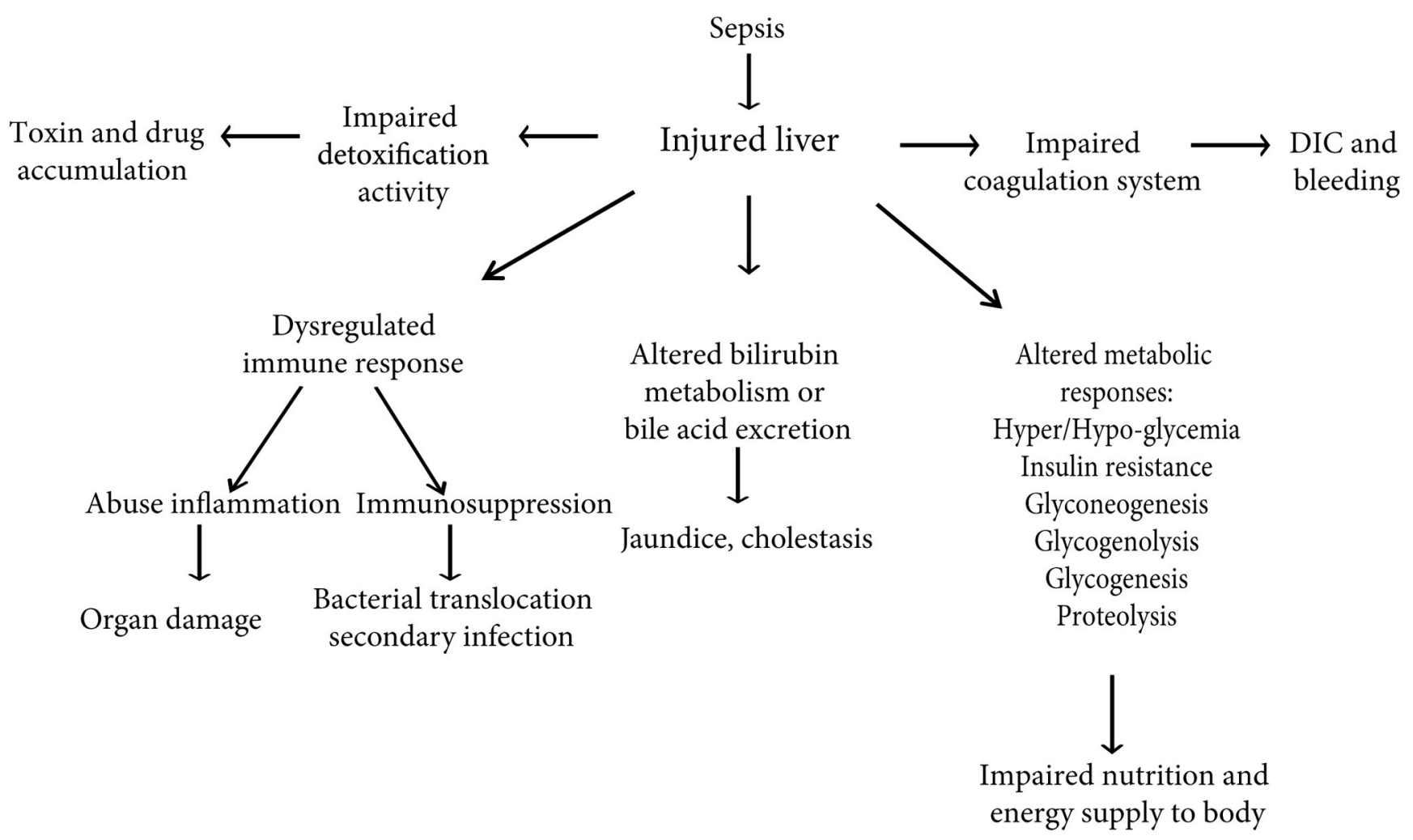

Figure 3.

Hepatic responses and functions in patients with sepsis. Abbreviations: DIC, disseminated intravascular coagulation. 


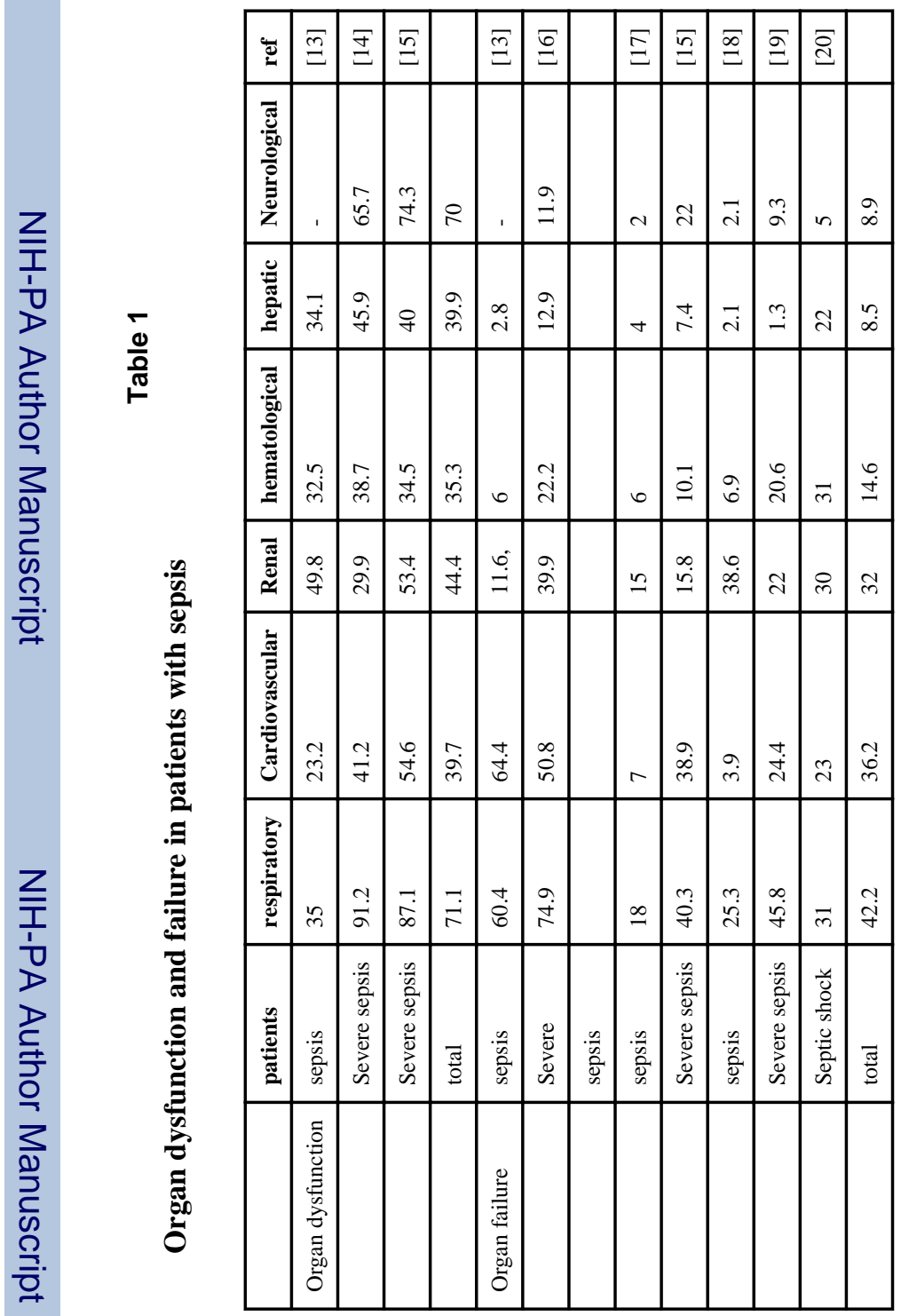

Int Rev Immunol. Author manuscript; available in PMC 2015 November 01. 


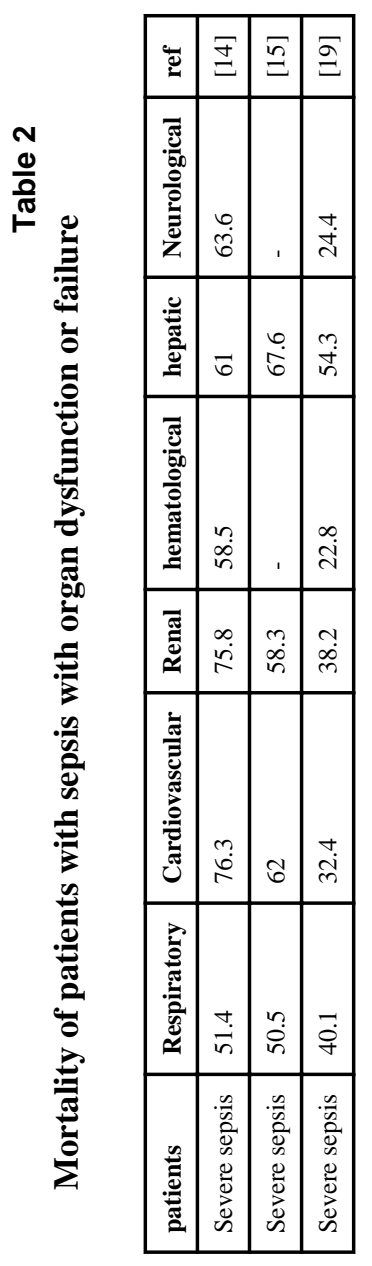

Int Rev Immunol. Author manuscript; available in PMC 2015 November 01. 